\title{
O cinema de Josafá Duarte no sertão do Brasil: feito pelo povo, para o povo
}

\author{
Paulo Passos de Oliveira ${ }^{1}$
}

\section{Introdução}

Este trabalho apresenta o produtor, roteirista, cineasta e ator Josafá Duarte, morador do distrito de Salgado dos Mendes, município de Forquilha, zona Norte do Estado do Ceará, na região Nordeste do Brasil. Josafá - que tem na agricultura familiar sua principal ocupação - começou a fazer cinema com a intenção de promover o que ele chama de "conscientização política". Seu cinema, que milita em prol do desenvolvimento da cidadania, é indissociável de sua história de vida: ao longo de sua jornada, Josafá foi líder comunitário e ativo membro do Movimento dos Trabalhadores Rurais Sem Terra (MST). Pertencente às classes sociais populares, Josafá define o cinema que produz como "popular". O foco da análise deste artigo é a constituição do que será definido como cinema popular e sua relação com outro importante conceito: cultura popular. O tipo de cinema realizado por Josafá bem como suas práticas de exibição apontam para a necessidade de se reconfigurar a história do cinema, além das produções exibidas em salas de cinema comerciais. Essa prática desencadeia a necessidade de repensar as manifestações cinematográficas tendo em conta a importância do trabalho dos pequenos realizadores em suas comunidades e a difusão de suas obras na Internet.

No Brasil, atualmente, há crescente bibliografia sobre o tipo de cinema feito à margem dos mecanismos oficiais de produção e de exibição. Os livros Cinema de bordas, organizado por Bernardete Lyra e Gelson Santana (2006), Cinema de garagem: um inventário afetivo sobre o jovem cinema brasileiro do século XXI, de Dellani Lima e Marcelo Ikeda (2010), e Catadores de sucata da indústria cultural, que resulta da pesquisa realizada por Alice Fátima Martins (2013), são três importantes exemplos de obras que ampliam o debate sobre a produção audiovisual desenvolvida por pessoas comuns, sem formação acadêmica em linguagem ou produção de cinema. O cinema realizado por estes produtores vem sendo, aos poucos, objeto de estudo e de pesquisa na academia brasileira. As dissertações de mestrado Filmes periféricos e as margens do cinema brasileiro: um estudo de caso a partir do longa-metragem Cartão Postal (Santos 2016) e Entre fazendeiros, donzelas e caiçaras: uma semiose cinematográfica de Cyro Matoso (Abbema 2013) são apenas dois exemplos de como o cinema realizado fora dos eixos de produção profissional vem a encontrar nas universidades campo de debate e estudo.

A relação entre cinema popular e cultura popular, estabelecida neste artigo a partir da produção de Josafá Duarte, tem como objetivo contribuir para esta discussão. Decerto, o termo cultura, também constituído histórico-sócio-

1 Programa de Pós-Graduação em Arte e Cultura Visual/Faculdade de Artes Visuais, Universidade Federal de Goiás, CEP 74.690-900 Goiânia, Goiás, Brasil. 
geograficamente, ganha importante dimensão no universo epistemológico contemporâneo, a partir das análises das transformações sociais, que passam a ser percebidas como um fenômeno.

O texto aqui apresentado está estruturado em quatro partes a partir da narrativa biográfica de Josafá Duarte. Estabelecida como relação, a narrativa de vida pode ser entendida também como uma ação social (Delamont 2006). O processo de criação no cinema é, também, um processo "(auto)biográfico", no momento em que a "biografização" acontece na experiência do sujeito, pois, nos momentos em que cria histórias e as grava, o cineasta enuncia suas referências, um círculo de memórias preenchidas por afetos e informações vivenciadas. Este artigo é fruto de quatro entrevistas realizadas com Josafá Duarte, e que não foram publicadas: três presenciais e uma por telefone. A primeira entrevista, presencial, foi registada em áudio, em 23 de agosto de 2013; a segunda, gravada por telefone, em 02 de maio de 2016; a terceira e a quarta, presenciais, gravadas em vídeo digital, em 26 e 27 de janeiro de 2017. Todas as perguntas foram ordenadas em um guião, de forma semidiretiva, na intenção de promover uma conversa livre e fluida. As entrevistas subsidiaram a maior parte dos dados sobre a vida e a obra de Josafá Duarte, expostos ao longo de todo o texto.

A segunda parte do artigo apresenta a prática de gravação de Josafá Duarte. No final do ano de 2016, Josafá Duarte sugeriu fazer um filme de curtametragem, gravado em um dia, para que fosse possível acompanhar todo o processo de realização. O cineasta começou a planear Escapei fedendo (Josafá Duarte 2017), filme de menos de 7 minutos, gravado em 07 de fevereiro de 2017, no qual o autor deste artigo participou como ator em uma pequena sequência. Esta secção destaca não apenas a dinâmica de gravação, mas também as relações estabelecidas entre os membros da equipa no ato da realização cinematográfica. A participação do autor do artigo como ator nesta produção e a observação do processo de gravação foram registadas em diário de campo. As informações contidas nesta secção têm origem nos registos de campo, realizados com base no método etnográfico.

A terceira parte do artigo analisa as estratégias de exibição e de publicização dos filmes de Josafá Duarte. Neste sentido, é necessário destacar a importância do uso de ferramentas da Internet e a relação com o poder público municipal com vista à exibição pública presencial de sua obra em Forquilha. $\mathrm{O}$ advento de tecnologias de comunicação em rede a partir do universo digital por si só não resolve a difusão da obra dos cineastas populares em contexto de sua própria localidade. Neste caso, o cineasta necessita do apoio do poder público municipal, tanto para a realização do Festival de Cinema de Forquilha, como para exibições na área rural do município.

A produção de filmes de baixo custo, com equipamento amador, realizados por pessoas sem formação teórica em audiovisual ou artes cênicas, ainda não encontrou um conceito ou terminologia capaz de agregar, ao mesmo tempo, a multiplicidade de filmes, temáticas, narrativas, as diversas características de formas de produção e os múltiplos olhares daqueles que assistem aos filmes brasileiros. Portanto, em um quarto momento deste texto, será apresentada uma discussão sobre o tipo de cinema realizado por Josafá Duarte, e alguns conceitos sobre este tipo de cinema para circunscrever o tipo de filme que ele pratica e os aspectos de produção que são envolvidos na realização. Em entrevistas, Josafá usa o termo "cinema popular" quando se refere 
ao seu próprio cinema. A noção de cinema popular dialoga com o próprio conceito de cultura, que traz consigo a ideia de dinâmica, plasticidade e mudança. O que é compreendido na esfera popular permanece no cotidiano e nas produções coletivas, e sua existência é transmitida no tempo e no espaço. A cultura popular faz-se concentrando e consumindo outras formas de tecnologias, materiais e padrões, antes inacessíveis aos homens do povo (Chartier 1995).

Além do diário de campo e das entrevistas, foi promovida investigação do blog Forquilha Cinecordel (Roger 2013) e do canal de Josafá Duarte no YouTube (Duarte 2016), desde o primeiro semestre de 2017 até o período de finalização da redação deste artigo, no fim de março de 2019. A observação do conteúdo audiovisual disponível na Internet permitiu verificar a amplitude da recepção do filme Escapei fedendo (Josafá Duarte 2017) na rede.

\section{Um cineasta no sertão nordestino brasileiro}

Josafá Ferreira Duarte, 58 anos, é morador de Salgados dos Mendes, distrito com cerca de 500 habitantes que pertence à cidade de Forquilha. Este município está localizado a $200 \mathrm{~km}$ ao norte de Fortaleza, capital do Estado do Ceará, no Nordeste do Brasil. Agricultor e cineasta, Josafá está entre aqueles que se apropriaram do cinema como forma de resistência para, nos filmes de ficção, continuar transmitindo uma visão muito particular dos elementos de sua cultura local. Sem projetos estéticos e manifestos definidos, o realizador do sertão vai ocupando, como diria o poeta João Cabral de Melo Neto (2007), "a parte que lhe cabe deste latifúndio" da cultura popular, e gera o cinema popular, termo fundamental para refletir sobre o que é o cinema contemporâneo praticado no Brasil. Esta discussão, cerne deste trabalho, será retomada na quarta secção.

A biografia de Josafá marca o ponto fora da curva. Afinal, como um agricultor, morador de uma pequena localidade, isolada dos grandes centros, sem equipamentos culturais legitimados socialmente - museus, teatros, bibliotecas, galerias de arte, cinemas -, conseguiu encontrar motivação para fazer filmes? A resposta está em sua liderança social. Para tanto, é necessário narrar parte de sua história de vida.

Josafá migrou com sua família para Fortaleza no ano de 1977. Como a maior parte das famílias que mudavam do interior para a capital, o grupo familiar de Josafá buscava melhores oportunidades de trabalho. Àquela época, Josafá tinha 17 anos de idade.

Em sua vida profissional, Josafá fez de tudo um pouco: foi contínuo ${ }^{2} \mathrm{em}$ uma construtora por seis anos, vendeu terrenos em São Luís, no Estado do Maranhão, mas, ao retornar a Fortaleza, tornou-se fotógrafo. Exerceu esta atividade por 15 anos. É possível afirmar que daí surgiu sua afinidade pelo registo de imagens. Josafá fotografava batizados, aniversários, crianças, etc. Prestava seu serviço em localidades periféricas de população pobre, como a Vila Manoel Sátiro, o Parque Santa Rosa, Parque São José, dentre outros lugares. Todos os bairros estão localizados próximos à favela em que ele morava: a comunidade da Baixa da Jumenta. Foi lá que Josafá começou a desenvolver sua liderança social: fundou uma associação de moradores e criou um grupo de teatro.

\footnotetext{
${ }^{2}$ Funcionário de empresa encarregado de fazer entregas de produtos e documentos, depósitos e pagamentos em bancos, entre outras tarefas afins.
} 
Ao final dos anos 90, ingressou no Movimento dos Trabalhadores Rurais Sem Terra (MST) ${ }^{3}$. Josafá encontrou no Movimento apoio para ajudar famílias de sua comunidade que viviam em condições precárias, a habitar casas feitas de papelão. Com o apoio do MST, cadastrou 40 famílias que viviam de forma miserável e, em seguida, começou a procurar fazendas que tivessem o perfil de desapropriação pelo Instituto Nacional de Colonização e Reforma Agrária (Incra) ${ }^{4}$ com a finalidade de realocar estas famílias.

Em uma das ações, no ano de 1997, Josafá e seus companheiros do MST conseguiram assentar 40 famílias na fazenda Lagoa Grande, de 1600 hectares, no município de Pentecoste, a $89 \mathrm{~km}$ de Fortaleza. Neste sítio, Josafá viveu durante cinco anos, época em que lutou pela legalização da terra, pelo estabelecimento de infraestrutura e pelo financiamento das lavouras. Em entrevista, Josafá Duarte (Oliveira 2017) explicou que liderar um grupo de 40 famílias não foi fácil, pois estavam em jogo diferentes interesses e expectativas diante de uma nova realidade que se impunha.

Os conflitos internos, inerentes às relações humanas no assentamento, eram mais fáceis de administrar do que aqueles que aconteceram com os antigos funcionários da fazenda. Desde o início da ocupação, os trabalhadores que lá estavam não aceitaram os novos ocupantes. A situação complicou-se com a mistura dos gados bovinos de criação dos antigos empregados, e os adquiridos pelos novos moradores, com financiamento do Incra. Como retaliação, Josafá foi ameaçado de morte por capatazes do ex-fazendeiro. Após passar 10 dias sob proteção da Polícia Federal, decidiu que era hora de retornar a Salgado dos Mendes e voltar a viver da agricultura. O ano era 2002.

Ao chegar à sua terra natal, Josafá decidiu se afastar da liderança social. No entanto, descobriu uma série de vícios políticos em sua comunidade, como a troca de votos por dinheiro e garantia de emprego na prefeitura de Forquilha para os apoiadores políticos do gestor municipal. Foi quando Josafá decidiu estabelecer algum mecanismo de conscientização que possibilitasse à população se livrar dos políticos tradicionais. No ano de 2006, resolveu fundar o Jornal Sociedade Salgadense, que foi editado até o ano de 2015.

O jornal - feito em computador caseiro, quase sem recursos financeiros cumpriu importante papel político para veiculação de demandas da sociedade de Salgado dos Mendes e de denúncias sobre problemas políticos. Entretanto, ainda no ano de 2006, Josafá se deparou com um problema: parte da população de Forquilha, e em especial de Salgado dos Mendes, era analfabeta, portanto não tinha acesso às informações publicadas no jornal. Foi quando teve a ideia de fazer

\footnotetext{
${ }^{3}$ O Movimento dos Trabalhadores Rurais Sem Terra (MST) é um movimento social que surgiu no Brasil, em 1984, como resposta ao modelo de reforma agrária proposto pelo governo militar, que priorizava a "colonização" de terras devolutas em regiões remotas do país. O projeto governamental acabava por relegar famílias à própria sorte, condenadas a cultivar terras impróprias para o uso agrícola, em territórios inóspitos. Atualmente, o Movimento luta para que a reforma agrária seja fielmente implantada, conforme previsto no artigo 184 e seguintes da Constituição Federal aprovada em 1988.

${ }^{4}$ O Instituto Nacional de Colonização e Reforma Agrária (Incra) é uma autarquia federal, cuja missão prioritária é executar a reforma agrária e realizar o ordenamento fundiário no Brasil. A reforma agrária, por sua vez, é uma ação prevista na Constituição Federal brasileira e visa tornar a distribuição de terras mais justa. Dentre os critérios previstos para a desapropriação de um sítio está aquele que exige que a terra seja improdutiva, a saber, a propriedade rural que, embora agricultável, encontra-se total ou parcialmente inexplorada pelo seu ocupante ou proprietário.
} 
cinema. Ele acreditava que seus filmes teriam maior capilaridade que o jornal, sobretudo com relação à população com menor grau de escolaridade. No início, ninguém queria ajudá-lo. Ele enfatiza esta situação em sua fala:

Ninguém quer ajudar nada, 'tá tudo contra nós, então vamos provar que somos mais fortes que esses obstáculos que têm sempre na vida da gente, e vamos começar a fazer sem saber fazer. Sem saber fazer. Vamos fazer sem saber fazer. Essa tem sido a nossa teoria, entendeu? De aprender com nossos erros, de aprender a fazer aquilo que muitas pessoas acham que a gente não é capaz de fazer e aí vamos fazer do nosso jeito. (Oliveira 2016, grifo do autor). ${ }^{5}$

Com uma câmera de VHS emprestada, realizou A história de um galo assado (Josafá Duarte 2006). Josafá continuou a pelejar: entre equipamento emprestado e a colaboração de amigos, após cinco filmes editados "na ordem em que se filma", participou de cursos ligados ao universo audiovisual em sua cidade natal e em Sobral, município polo da região em que vive, localizado a $22 \mathrm{~km}$ de Forquilha.

Aos poucos, a comunidade começou a se envolver com as produções do cineasta: uma vizinha faz a maquiagem, um amigo ajuda com a câmera, outro faz o lanche, Josafá dirige e, na maioria das vezes, atua. Dessa forma, surgiu o grupo colaborativo "Cinecordel", cujo nome remete à forma de literatura popular de origem lusitana, encontrada, sobretudo, no Nordeste brasileiro ${ }^{6}$. Dessa forma, o cineasta de Forquilha homenageava seu pai, antigo trovador e violeiro, que, aos 88 anos, ainda mora em Salgado dos Mendes.

O grupo colaborativo é fundamental para a realização dos filmes. A esposa de Josafá, Noélia Duarte, é uma grande incentivadora, sempre a produzir e gerenciar por trás das câmeras, e muitas vezes a atuar na frente delas. Aureliano Shekinah, outro colaborador e amigo, ajuda com a câmera e com o uso de tecnologias, que são, até hoje, para Josafá, de difícil utilização.

Josafá produz em alta profusão - chega a fazer entre três e quatro filmes ao ano. Nos últimos 13 anos, ele realizou 30 filmes de ficção, a maioria de média e longa-metragem. Neste sentido, em função da urgência que sente em produzir, pequenos detalhes técnicos - como os que dizem respeito à continuidade podem ser negligenciados.

Suas comédias, sempre feitas em Salgado dos Mendes e na sede Forquilha, tratam prioritariamente de situações de desmandos políticos: corrupção, compra de votos e injustiças sociais. Entretanto, Josafá já realizou filmes infantis que abordam questões ambientais, como Pássaros Fantasmas: aventura na selva (Josafá Duarte 2014b).

\footnotetext{
${ }^{5}$ Ao gravar a oralidade de Josafá, um elemento chamou a atenção: sua maneira rápida de falar. Ela marca sua personalidade, fala de si e sobre si. Por isso, ao longo deste artigo, quando é reproduzida a fala de Josafá, registada em entrevista, optou-se por repetir na forma escrita a sua oralidade, com suas nuances rítmicas de fala e a flutuação do seu pensamento.

${ }^{6}$ A literatura de cordel chegou ao Brasil no século XVIII trazida pelos colonizadores portugueses. Essa forma de literatura era escrita por artistas que improvisavam cantos - que originam os repentes e emboladas - e que viajavam a apresentar a sua arte e a ganhar algum dinheiro, sobretudo em parte do Nordeste brasileiro. Foi assim que este tipo de literatura se tornou popular e acessível. Dentre seus temas estão presentes tradições culturais regionais do homem do sertão. No Ceará, onde vive Josafá Duarte, o cordel pode ser encontrado em larga escala nas feiras de rua localizadas na região do Cariri, no Sul do Estado.
} 
Os filmes produzidos por Josafá costumam vislumbrar o universo do homem do sertão: lendas, gírias e expressões idiomáticas, a lida no campo, histórias de traição, a vizinha fofoqueira, tudo realizado com muito bom humor. As suas histórias costumam ser inspiradas em personagens e situações típicas de sua localidade.

A linguagem dos filmes de Josafá pode ser identificada como "narrativa clássica": histórias lineares, sem narradores em voz off, sem fluxos de flashback, com começo, meio e fim (Bordwell, Staiger, e Thompson 2015). Os filmes de Josafá Duarte, em consonância com a narrativa clássica, possuem coerência e mantêm a tradição das fábulas, ou seja, os eventos ocorrem em ordem cronológica e, embora tenham como finalidade a "conscientização política" por parte de quem assiste, a narrativa não se submete a contestações. Dessa forma, o texto falado, as imagens e o som são complementares. As falas dos personagens ocorrem na primeira pessoa. Toda narrativa ocorre em uma consecução naturalizada e convergem para um fim.

Josafá Duarte aprendeu a fazer cinema na prática cotidiana. O início do seu aprendizado cinematográfico deu-se de forma autodidata. No entanto, Josafá só será considerado autodidata se este termo for interpretado em uma forma relacional: se for possível acreditar que o autodidata nunca se didatiza sem mediação, mas o prefixo auto é sempre sustentado semanticamente por agentes externos - pessoas ou coisas - ocultos no conceito. Josafá é autodidata, mas desde que se compreenda que o prefixo auto traz consigo a força de quem busca algo para si, mas com a certeza de que não está só no mundo. E que o mundo só é mundo quando "eu" sou junto aos "outros" e às "outras coisas"... e que sou mediado por eles.

O processo de mediação é relacional e está sempre presente com o outro. $\mathrm{O}$ ato de aprender e ensinar em grupo pode tomar como ponto de partida um "autodidatismo coletivo", que acontece no tempo e no espaço coletivos. Este processo será sempre compartilhado entre a equipa que faz cinema "sem saber fazer" e que busca soluções em grupo para problemas inerentes ao trabalho do colaborativo. Neste sentido, diante da troca compartilhada em grupo, é possível pensar que a base do aprendizado pode ser compreendida como grupodidática, no sentido que nos é apresentado por Lara Satler:

Por grupodidatismo compreendo a necessária presença do grupo na construção de saberes. Nesse sentido, [é fundamental], diante de autodescobertas, a proposição das mesmas em grupo. Assim, o sentido de grupodidatismo está na construção de saberes cuja validação se dá pela cooperação entre os sujeitos do grupo seja por intermédio de comentários que confirmem as descobertas pessoais, seja por aqueles que as questionem ou as ponham à prova. De qualquer modo, foi no grupo que os saberes se consolidaram [...] (Satler 2016, 129).

Josafá explica que encontrou inspiração para gravar em Casablanca (Michael Curtiz 1942), que teria visto "mais de 50 vezes", em O auto da compadecida (Guel Arraes 1999), em novelas brasileiras e em seriados norteamericanos que assistiu na TV. O filme $O$ auto da compadecida, que também foi exibido na TV brasileira em formato de minissérie, é baseado no livro homônimo de Ariano Suassuna e aborda as estratégias de João Grilo para sobreviver, homem simples do sertão, às voltas com as injustiças da polícia, de coronéis e de 
cangaceiros $^{7}$, sempre em tom farsesco e de comédia, universo próximo aos filmes de Josafá.

A importância do trabalho de Josafá foi reconhecida pelo cineasta Rosemberg Cariry - diretor do sucesso Corisco \& Dadá (1996) -, que emprestou a ele equipamento para a realização de Cadê meu zóculos (Josafá Duarte 2015), filme que ganhou versão em curta e longa-metragem. Cadê meu zóculos garantiu a Josafá o prêmio do júri popular no V Festival Brasileiro do Cinema Digital de Jijoca de Jericoacoara, no Ceará, em 2015. Foi o primeiro prêmio de porte nacional para um filme de Josafá Duarte. Em seguida, Cadê meu zóculos foi exibido no programa Diário de Cinema, em 2016, na TV Diário, canal aberto do grupo Diário do Nordeste, presente no Estado do Ceará. Além deste, foi exibido ainda $O$ homem que queria enganar a morte (Josafá Duarte 2014a). O cineasta participou do programa comentando seus filmes.

\section{Josafá Duarte e a prática de gravação}

Para compreender melhor os mecanismos de realização cinematográfica de Josafá Duarte foi necessário participar de seu processo de produção. A experiência levada a cabo no dia 08 de fevereiro de 2017, data da gravação do curta-metragem Escapei fedendo (Josafá Duarte 2017), permitiu entender como são desenvolvidos os aspectos técnicos de gravação. A observação do processo de gravação permitiu, sobretudo, a compreensão - registada em diário de campo - das relações interpessoais entre os membros da equipa de gravação.

Escapei fedendo (Josafá Duarte 2017) retrata uma situação política em tom de comédia: um cangaceiro, interpretado pelo próprio Josafá Duarte, caracterizado com um chapéu e uma peruca de cabelos compridos e desgrenhados, aponta uma espingarda para o funcionário da prefeitura interpretado por "Cabecinha" - da cidade fictícia de Barro Vermelho, que está sobre os degraus de uma escada, apoiada na parede da frente de uma igreja. $\mathrm{O}$ funcionário foi incumbido pelo prefeito corrupto de retirar o sino da torre, e o cangaceiro tenta impedi-lo. Ao lado do cangaceiro estão o padre da referida igreja e mais seis moradores da cidade. Vale ressaltar que o prefeito foi vivido também pelo próprio Josafá Duarte, que assumiu a função quando o ator escalado não pôde comparecer. Dessa forma, Josafá interpreta dois personagens na mesma produção.

A estrutura clássica narrativa é clara neste curta-metragem: os personagens são apresentados no início da trama. Na segunda sequência, o espectador conhece quase todos os personagens, e qual o conflito que será desenvolvido. Por volta da metade do filme, acontece a virada, momento em que a ação deixa a frente da igreja e passa para o interior da casa de uma das personagens, que liga para o prefeito cobrando satisfação sobre a retirada do sino da torre da igreja. A resolução fica evidente na última sequência, momento em que a trama é resolvida com a prisão do edil corrupto.

\footnotetext{
7 Cangaceiros eram anti-heróis armados que vagavam em bandos pelos sertões do Nordeste brasileiro, sobretudo, ao longo das três primeiras décadas do século XX. Embora não existam mais, os personagens relativos ao mundo do cangaço ainda povoam o imaginário popular de quem vive naquela região brasileira. Estão presentes na literatura, no cinema, em novelas e em seriados de TV.
} 
O processo de preparação e de gravação foi simples e rápido. Um pouco depois das 7h00, Josafá se reuniu com os atores do filme e o cameraman - o único integrante com função técnica - no alpendre de sua casa. Ele expôs como seria realizado o filme, deu instruções e explicou como deveriam ser as falas e as atuações. Em seguida, os atores - todos membros da comunidade de Salgado do Mendes, sem formação em Artes Cênicas - se caracterizaram com suas próprias roupas. Após as gravações, Josafá informou que decorar textos era uma tarefa difícil para atores não profissionais. Enquanto isso, para efeito de análise do processo do registo audiovisual, foram sendo tomadas notas em diário de campo.

Durante a etapa de preparação para a gravação, Josafá, inusitadamente, criou um personagem para ser interpretado pelo autor deste artigo. O cineasta tem o hábito de convidar os que estão presentes no set de gravação para participarem de alguma cena específica, e cria o personagem pouco antes do registo audiovisual. O personagem inventado para o pesquisador era o de um "turista" que se juntava ao grupo que observava o clima tenso entre o cangaceiro e o funcionário a quem foi atribuída a tarefa de retirar o sino da torre da igreja.

As primeiras cenas foram gravadas a partir das $8 \mathrm{~h} 30 \mathrm{~min}$ em frente à igrejinha de Salgado dos Mendes, localizada em uma praça, ao lado da casa de Josafá. Em determinado momento, Aureliano Shekinah, que operava a câmera, assumiu, como ator, o papel de "delegado de polícia”. Neste momento, Noélia Duarte, esposa de Josafá, passou a operar a câmera.

A relação entre o diretor e a equipa obedece a afinidades e amizade, manifestadas durante o ato de gravação. Dessa forma, é comum os atores em cena interromperem a gravação para opinarem sobre a atuação de algum colega, e auxiliar o trabalho de algum novo ator. Neste sentido, o diretor não é o único que pode interromper o processo de gravação.

Josafá grava muito rápido e reina a informalidade no set de filmagem. Mais tarde, Josafá explicou que os atores do seu filme têm pressa para retornar para os seus afazeres cotidianos: preparar o almoço, cuidar da casa, retornar para o comércio em que trabalham.

Sem o recurso de plantas-baixas ou storyboards, Josafá revelou que tem o planeamento de suas cenas quase todo em sua mente. O guião se resume a uma folha de papel escrita a mão. Em caso de dúvida, este roteiro pode ser consultado por qualquer membro da equipa durante as gravações. No entanto, o guião não impede que Josafá improvise e crie alguma situação nova para o curta-metragem durante o ato das gravações.

A realização de filmes é comum naquela região. Durante a gravação, foi possível constatar que as pessoas que passaram pela praça, transformada em pequeno set de gravações, olhavam sem muita curiosidade. Uma senhora da comunidade passou ao lado do grupo que realizava o filme. Ao observar que o pesquisador era alguém de fora da comunidade, disse que Josafá continuava a fazer suas "maluquices". O pesquisador apenas sorriu e disse que admirava o trabalho do diretor. A senhora sentiu-se um pouco constrangida e seguiu seu caminho. Foi possível inferir que nem todos os moradores de Salgado dos Mendes levam a sério o trabalho desenvolvido por Josafá.

Após concluir o registo das cenas externas, Josafá correu para sua casa, cujo interior serviria de cenário para as cenas internas. No momento em que Aureliano Shekinah preparava a iluminação, Noélia Duarte terminava de 
temperar o almoço. Josafá voltou a instruir os atores que participariam das cenas e, rapidamente, Shekinah passou a se ocupar de descarregar o conteúdo gravado no antigo computador de mesa de Josafá. O computador foi um presente que o diretor ganhou de seu filho mais velho.

Ao fim da gravação de novas cenas, parte da equipa foi almoçar na casa do diretor, enquanto outra parte, que morava próximo a ele, preferiu almoçar em casa. Durante pouco mais de uma semana, Josafá ocupou-se de editar seu filme em um software gratuito e, em seguida, postou o curta-metragem em seu canal do YouTube (Duarte 2016). Disponível na Internet desde 16 de fevereiro de 2017, Escapei fedendo (Josafá Duarte 2017) recebeu mais de 3600 visualizações até abril de 2019.

\section{Josafá Duarte e as formas de exibição}

As produções de longa-metragem de Josafá Duarte geralmente são lançadas em Salgado dos Mendes nos poucos espaços públicos disponíveis, como a quadra poliesportiva do distrito, localizada atrás da mesma igreja que serviu de cenário para Escapei fedendo (Josafá Duarte 2017). No lançamento, as cópias em DVD também são vendidas a baixo custo. Os filmes costumavam ser disponibilizados gratuitamente na Internet, no blog Forquilha Cinecordel (Roger 2013), criado com a finalidade de divulgar o trabalho e exibir os filmes de Josafá e de seus colaboradores. O acesso ao blog em 08 de abril de 2019 revelou que este espaço da Internet não é atualizado desde maio de 2015, quando foi postado o filme $O$ casamento de Vicência (Djalma Prado 2011), inspirado no cordel escrito por Luís Campos.

Os filmes de Josafá obtêm grande repercussão no YouTube (Duarte 2016). Em 2016, esta plataforma de postagem de conteúdo audiovisual na Internet pagou a Josafá o equivalente a 100 dólares convertidos em reais depois que Por debaixo dos panos (Josafá Duarte 2010) atingiu mais de 100 mil visualizações. Este filme é o mais conhecido do cineasta forquilhense. Segundo Josafá, Por debaixo dos panos foi copiado por distribuidores de camelôs e vendido em vários Estados do Brasil com o nome de Zé das Cachorras. Na época, o cineasta não ficou chateado com a pirataria, alegando que a multiplicação das cópias de seus filmes, conforme seu depoimento, "é sinal de que o povão 'tá gostando, né?!" (Oliveira 2013).

Em 2016, o YouTube passou a desempenhar novo papel na carreira do realizador de Forquilha. Em entrevista realizada por telefone, Josafá informou que começou a desenvolver uma série infantil focada em questões ambientais específica para o canal da Internet (Duarte 2016).

O sucesso do trabalho de Josafá Duarte motivou o surgimento de outros cineastas em sua região, como Paulo Talentos, Ronaldo Roger e o já citado Aureliano Shekinah. Liderado por Josafá Duarte, o grupo foi responsável pelo Festival de Cinema de Forquilha, cuja primeira edição foi realizada entre 14 e 16 de fevereiro de 2014. Em todas as três edições realizadas, entre 2014 e 2016, Josafá teve filmes premiados. A realização do Festival de Cinema de Forquilha foi feita em parceria com a Secretaria de Cultura do município.

Josafá pode ser disposto na categoria de emancipação no sentido atribuído por Zygmunt Bauman (2001), na medida em que dribla os empecilhos, destaca a 
imaginação e investe na perseverança para com a finalidade de atuar na guerra pela libertação. Esta guerra passa pela relação entre o sujeito social e o Estado:

[...] verdadeira libertação [que] requer hoje mais, e não menos, da 'esfera pública' e do 'poder público'. Agora é a esfera pública que precisa desesperadamente de defesa contra o invasor privado - ainda que, paradoxalmente, não para reduzir, mas para viabilizar a liberdade individual (Bauman 2001, 62).

O poder público demorou a reconhecer o trabalho dos cineastas de Forquilha. Na primeira edição do Festival de Cinema de Forquilha, o único representante do governo municipal foi o secretário de Cultura. Em entrevista (Oliveira 2016), Josafá afirmou que foram investidos na realização do evento cerca de 10 mil reais - cerca de $2300,00 €$-, pouco diante dos quase 100 mil - 23 $000,00 €$ - destinados à realização do Festival de Quadrilhas ${ }^{8}$ da cidade, grande parte desta verba dedicada ao pagamento dos cachês de cantores e de bandas de sucesso.

O governo municipal, que nunca havia apoiado o trabalho dos cineastas de Forquilha, diante do sucesso da primeira edição do Festival de Cinema, apropriou-se do trabalho cinematográfico. Na segunda edição do Festival, realizada em 2015, o prefeito, secretários municipais, deputados estaduais e um deputado federal compareceram à festa de premiação e a transformaram em palanque político. Em área reservada, tomavam whisky, que era servido exclusivamente para as autoridades políticas. Nesta edição do Festival, Josafá conquistou o prêmio de Melhor Diretor pelo curta-metragem Cadê meu zóculos (Josafá Duarte 2015). Este filme ainda foi laureado com os prêmios de Melhor Ator, concedido a José Gustavo, e de Melhor Atriz, para Marliza Duarte, que são cunhado e irmã do cineasta.

O Cineclube é fruto de outro voo ao qual Josafá se lançou: a inscrição de projeto em edital. A formação do Cineclube começou após seleção da Secretaria da Cultura do Estado do Ceará (Secult) no ano de 2015. Entretanto, ele critica o modelo de edital desenvolvido ao dizer que:

Nós empregamos todo o dinheiro que veio, mas não era como eles queriam... como eles fizeram o modelo lá... nós 'tamo fazendo o projeto de cineclube, que era pra ser um ano e nós ‘tamo esticando pra dois anos... né?! (Oliveira 2017).

De acordo com as regras, Josafá não pode veicular seus próprios filmes. Mas, diante das limitações impostas pelo sistema, o cineasta forquilhense usa da

\footnotetext{
${ }^{8}$ Os Festivais de Quadrilhas são eventos que acontecem em inúmeras cidades brasileiras durante as Festas Juninas, que começam no dia 12 de junho, véspera do dia de Santo António, e encerram no dia 29 do mesmo mês, data em que se celebra São Pedro. Os dias 23 e 24 são dedicados a São João. Nas Festas Juninas predomina o ritmo musical conhecido como forró, muito executado na Região Nordeste do Brasil. A quadrilha é a dança típica da festa e consiste num animado baile, apresentado por um grupo vestido com trajes típicos, que culmina com o casamento de dois personagens. Um misto de dança e teatro, conhecido como casamento caipira, é realizado em homenagem a Santo António. O Festival de Quadrilhas apresenta vários grupos que disputam a maior animação, as vestimentas mais coloridas, a melhor dança, etc. As Festas Juninas foram introduzidas no Brasil pelos portugueses ainda no período colonial, mas sofreram influências das culturas africanas e indígenas, o que dá caráter distinto às suas manifestações em diversas partes do país.
} 
astúcia para divulgar e exibir as suas obras. Além dos filmes selecionados pela Secult, é exibida no Cineclube a produção local de Forquilha.

Os filmes e o equipamento são transportados em uma antiga Kombi branca, pertencente à Prefeitura Municipal de Forquilha, que traz nas laterais a frase "Forquilha: capital nordestina do cinema popular". O veículo transporta um computador, data show, écran, 100 banquinhos de PVC, o acervo de filmes em DVD, cabos e uma carrocinha com ingredientes para fazer pipoca. O motorista da Kombi era Aureliano Shekinah, um dos realizadores forquilhenses, cineasta que, até o ano de 2015, não possuía televisão em casa. Em fevereiro de 2017, a Kombi se encontrava quebrada, e o trabalho de exibição de filmes, suspenso. $\mathrm{O}$ veículo continuou inoperante durante muitos meses.

Após a cerimônia de premiação do II Festival de Cinema de Forquilha, no ano de 2015, o jovem prefeito Gerlásio Loyola - mais conhecido como "Play", que é a abreviação de "Playboy" - em conversa privada informou que pretendia fazer com que a Kombi circulasse o Estado do Ceará levando os filmes produzidos em Forquilha, com o objetivo de divulgar o seu trabalho frente à Prefeitura.

Josafá avalia que o apoio da Prefeitura à produção do cinema local é pequeno. Em entrevista, de maneira crítica, ele declarou:

Olha, nesses 10 anos de luta que nós temos aqui, a atual gestão, eles fizeram... deram um passo que eu acho interessante que foi o Festival de Cinema. Agora, uma segunda parte que eu acho que seria... [...] também pensar na parte... na parte financeira... dos produtores... um incentivo financeiro. [...] Eles têm que buscar... participar de editais. O próprio município participar de editais estadual e nacional pra ter recursos aqui pra Forquilha. Por exemplo, em 2015, nós perdemos aqui um projeto de uma sala de cinema porque a Secretaria de Cultura não fez o projeto a tempo. E era um projeto que veio para o Estado do Ceará e parece que voltou pra Brasília, pra Ancine', né, porque a gente 'tava em Jericoacoara [no Festival de Cinema Digital] e era o mês de julho, e esse projeto... que era 400 e pouco mil reais [pouco menos de $92000,00 €]$. E levar a ideia do cinema pras salas de aula, pras escolas, entendeu? [...] Porque lá, sim, é que vai realmente, vai afermentar essa ideia, né?! E vão surgir grandes produtores, grandes ideias (Oliveira 2017).

O depoimento acima revela que Josafá reconhece que o Estado desempenha importante papel na difusão e sedimentação do trabalho dos produtores de cinema de Forquilha. E lamenta porque o Estado não está preparado para assumir o cinema como importante dimensão cultural de Forquilha.

\section{Cinema popular: feito pelo povo, para o povo}

Josafá Duarte é um cineasta que faz parte do hall de realizadores de filmes que cresce em todo o Brasil. Acompanha Josafá o grupo de diretores e produtores formado por José de Oliveira, mais conhecido como Zé Pintor (São Carlos - SP),

\footnotetext{
${ }^{9}$ Ancine é a sigla que representa a Agência Nacional de Cinema, órgão responsável pelo fomento, regulação e fiscalização do cinema e do audiovisual no Brasil. A Ancine é uma autarquia especial criada em 2001, mas que, desde o ano de 2003, está vinculada ao Ministério da Cultura, com sede e foro no Distrito Federal, com Escritório Central no Rio de Janeiro, e dois Escritórios Regionais nas cidades de Brasília e São Paulo.
} 
Hugo Caiapônia (Caiapônia - GO), Martins Muniz (Goiânia - GO), Manoel Loreno (Mantenópolis - ES), somente para citar uma pequena parcela - a maioria pouco conhecida fora de suas localidades - daqueles que gravam com frequência suas histórias e narrativas nos lugares onde moram no Brasil. ${ }^{10}$

Estes roteiristas/produtores/diretores/atores/finalizadores, moradores de capitais ou de pequenas cidades, provavelmente não se conhecem. Eles não fazem parte de nenhuma academia ou associação formalizada por estatutos ou regimentos. Entretanto, o que os une é a capacidade de produção de filmes, a maior parte sem subsídios, fomento de leis de incentivo, nem de financiamentos, além dos poucos recursos financeiros pessoais ou de apoios de pequenos comerciantes das localidades onde vivem.

O aumento no quadro de pequenos produtores de filmes é um fenômeno contemporâneo e deve-se, entre outros motivos, à diminuição paulatina dos custos das tecnologias de captação de imagens e áudio, bem como dos computadores com softwares para edição de imagem e de som, sobretudo a partir dos anos 90 do século XX. Sobre esse fenômeno, Raimundo Martins $(2015,19)$ afirma que "a criação e disseminação da imagem em movimento oferece ao público a possibilidade de conjugar 'percepção crítica' e 'prazer estético', contrariando os cânones de uma prática erudita e desmistificando o rito da contemplação como uma fruição individualizada”. Tal percepção crítica e prazer estético, para Josafá Duarte, manifestam-se na sua visão política de fazer cinema.

De acordo com Alice Fátima Martins (2013), pelos mais diferentes motivos, os realizadores como estes descritos acima encontram no cinema a possibilidade de contar suas próprias narrativas. Segundo esta autora, autores como Josafá Duarte,

[...] movidos a paixão pelo cinema, dedicam seus esforços para assegurar, não só para si, como também para suas comunidades, [...] a aventura de contar suas próprias histórias, ainda que em condições precárias, e à revelia dos sempre onerosos orçamentos das produções cinematográficas disponíveis no mercado do entretenimento. [...] Tomam parte, sim, da corveia anônima, como cidadãos que, desconhecendo as adversidades, atuam em seus próprios contextos, construindo suas próprias narrativas, entre tessituras, diálogos e negociações sempre dinâmicas, entrecortadas por dificuldades e conflitos, sonhos e paixões (Martins 2013, 13).

Em um levantamento rápido, é possível verificar vários conceitos relacionados ao tipo de cinema feito por Josafá Duarte, e os outros realizadores citados acima: cinema de borda (Lyra 2009), de garagem (Lima e Ikeda 2010), de guerrilha - cuja paternidade não foi atribuída -, cinema paralelo (Le Masson e Poliakoff 1962), amador - no sentido proposto por Barthes (2009) -, periférico

${ }^{10}$ Sobre a biografia e a cinematografia desenvolvida por Manoel Loreno, é indicada a leitura de Martins (2013), livro que trata de um grupo de cineastas que trabalha à margem dos circuitos oficiais de produção e exibição. A autora desdobrou este trabalho na pesquisa intitulada Outros fazedores de cinema, financiada pela Fundação de Amparo à Pesquisa do Estado de Goiás (Fapeg) e pelo Conselho Nacional de Desenvolvimento Científico e Tecnológico (CNPq), em que mapeia as produções dos cineastas goianos Martins Muniz e Hugo Caiapônia. Sobre Zé Pintor, é sugerida a leitura do material disponível na Internet: a reportagem Zé, o pintor do cinema (Cabrera 2011) e a entrevista com Zé Pintor publicada na revista Rua (Sales 2012). Além dessas, há um filme feito sobre ele: Delírios de um cinemaníaco (Carlos Eduardo Magalhães e Felipe Leal Barquete 2013), disponível online. 
(Santos 2016), e imperfeito (Espinosa 1970) são apenas algumas das nomenclaturas criadas.

A questão não está em formular um único conceito que caracterize e dê significado ao cinema feito pelos realizadores fora do mainstream. O problema está colocado na grande quantidade de conceitos desenvolvidos por parte de acadêmicos, bem como pela crítica cinematográfica. Acreditamos que isso acontece devido a dois motivos:

1. À pequena distância histórica do início do fenômeno de existência deste tipo de cinema. Os eventos visuais ${ }^{11}$ necessitam de reflexão, investigação e debate dentro e fora da universidade, de maneira que se problematizem e se especifiquem os fenômenos para, então, apresentar conceitos;

2. Esta forma de manifestação cinematográfica não apresenta, necessariamente - embora existam -, manifestos unificadores, nem obrigatoriamente se insurge contra o cinema "oficial"; trata-se de um movimento plural que aponta para diversas motivações para realização de filmes por parte dos realizadores.

Quando questionado em três entrevistas sobre o tipo de cinema que realiza, Josafá Duarte o definiu como “popular” (Oliveira 2013, 2016, 2017). Este termo, usado pelo sujeito deste artigo, traz consigo a acepção de "cultura popular" no sentido de manifestação feita "pelo povo" e "para o povo". O conceito de "cultura popular", longe de ser uma unanimidade na área das ciências sociais, aporta aqui o que pesquisadores e professores entendem como o conjunto dos que compõem o pensamento representativo de uma dada sociedade, em um contexto histórico, geográfico e social (Chauí 1996). Dessa forma, as produções de Josafá são referidas, aqui, no âmbito do “cinema popular".

Raymond Williams (1965) descreve cultura como um modo de vida total por onde circulam significados e valores presentes nas instituições da vida social. A cultura não é imanente e vai além das esferas da educação e arte. Por isso, a cultura pode ser reinventada pelos excluídos das instituições culturais - os que não têm acesso a museus, teatros, cinemas, bibliotecas, etc. (Luna 2010). Esses excluídos - ausentes das instituições porque são invisibilizados socialmente são desafiados a "reinventar" os elementos culturais à sua maneira. Este é o caso de Josafá Duarte, que adentra no campo da cultura como quem penetra uma "arena de luta". Portanto, neste caso, pensar a luta cultural implica refletir sobre a visibilidade da produção dos cineastas populares, o papel desempenhado por esses realizadores em suas regiões. Para Josafá, o seu cinema possui um caráter iminentemente político, e é concebido como em uma arena cultural de luta.

Stuart Hall (1997, 15) enfatiza a "centralidade da cultura [e] a enorme expansão de tudo que está associado a ela, na segunda metade do século XX, e o seu papel constitutivo, hoje, em todos os aspectos da vida social". Portanto, ainda que não tenha sido plenamente verbalizado pelo cineasta de Forquilha, o termo

11 "O conceito de evento visual inclui toda situação de observação tal como ocorre na interação entre o observador, o fenômeno visual, o contexto de observação e o ato de olhar propriamente dito. Eventos visuais são sempre situados geográfica, histórica, social e culturalmente, implicando certa interação ou posicionamento entre o observador, o fenômeno observado, o contexto e o olhar" (Illeris e Arvedsen 2012). 
"cinema popular" dialoga diretamente com a categoria "cultura". Não é viável pensar, hoje, em cultura erudita e cultura popular sem considerar a cultura de massa (Hall 2014). Por outro lado, cultura de massa não eliminou a cultura popular: em certa medida, ela a absorveu como produto.

\section{Considerações finais}

O sujeito da contemporaneidade é, antes, um produtor e consumidor de imagens. Josafá, assim como Zé Pintor, Hugo Caiapônia, Martins Muniz e Manoel Loreno, faz parte do grupo de cidadãos comuns que, apropriando-se do cinema, tornamse fazedores de imagens - e sons - em movimento. Ao (re)criá-las, tomam como base referenciais culturais das comunidades em que vivem.

Josafá Duarte é um cineasta que se relaciona com as imagens de seu tempo. A cultura visual contemporânea é caracterizada pela habilidade de fazer viajar os elementos visuais, ao romper com o lugar onde são produzidos. A interiorização de imagens e linguagens cinematográficas universais, apropriadas por Josafá de acordo com referenciais culturais locais de sua região, permitem ressignificação, o que gera o seu cinema popular.

De maneira inversa, o cinema de Josafá Duarte ganha o mundo a partir de suas estratégias de exibição. A história de vida do cineasta forquilhense revela que a publicização de sua obra pode ser compreendida a partir de dois eixos. $\mathrm{O}$ primeiro estaria no âmbito da apresentação pública, coletiva e presencial, definido pela exibição nas localidades de Salgado dos Mendes especificamente e de Forquilha, de maneira geral; também podem ser enquadradas como exibições públicas aquelas circunscritas aos festivais. O segundo pilar seria o da disponibilização nas mídias digitais, normalmente restringidas a visualizações privadas, não presenciais e, normalmente, individuais, caracterizada pelas postagens de filmes em canal do YouTube e, em tempos mais remotos, no blog Forquilha Cinecordel. Além da Internet, os filmes de Josafá também são encontrados em DVD, sejam aqueles vendidos diretamente pelo cineasta, sejam aqueles negociados por comerciantes desconhecidos, a partir de cópias não autorizadas.

As duas formas de exibição também evocam diferentes - e tensas relações entre o cineasta de Salgado dos Mendes e o poder público. A realização de filmes populares é um ato de criação que não demanda ajuda do poder público. Entretanto, a exibição pública tem maior alcance com a participação da prefeitura municipal, com a realização do Festival de Cinema de Forquilha, bem como com a cessão da Kombi com todos os instrumentos para a viabilização de um "cinema itinerante". Além do apoio do governo municipal, o projeto de realização de cineclube, previsto em edital do Governo do Estado do Ceará através da Secult, tornou possível a interiorização dos filmes de Josafá, ainda que de forma clandestina, à revelia do edital.

Refletir sobre a identidade nacional do cinema brasileiro passa, hoje, pelo reconhecimento do cinema popular, realizado com baixo orçamento e com parcos recursos técnicos e teóricos. Neste sentido, é preciso pensar a constituição do cinema como constante devir, por vezes, projetado em écrans brancos, ora ejetado de écrans planos; às vezes, analógico e exibido para um grupo; em outros momentos, digital e acessado para um espectador solitário, mas sempre cinema enquanto narrativa de imagem em movimento e som. É 
necessário alargar, então, o próprio conceito de cinema ao considerar a absorção de novas tecnologias referentes a outros mecanismos de produção e de exibição, além das salas comerciais de cinema. Dessa forma, entre o espaço público e o privado (uma exibição coletiva em Salgado dos Mendes e o indivíduo solitário à frente da tela do computador), está o espectador dos filmes de Josafá. Portanto, é necessário aceitar que o cinema popular é aquele que não está presente nas distribuidoras mainstream: não obedece à prospecção de lucro, nem planejamento de mídia ou de distribuição. Entretanto, na sua informalidade, circulam elementos fundamentais para pensar a cultura popular e a nova configuração do próprio cinema.

As questões colocadas ao final deste texto evocam o papel do poder público no contexto do trabalho executado pelos cineastas populares. Mesmo uma pequena cidade, como Forquilha, encontra no espaço de uma sala de cinema as condições de formação e de sedimentação de públicos específicos. O cinema, aquele espaço físico de fruição de experiências visuais, ainda ocupa o imaginário e o desejo do cineasta de Forquilha. Defensor da realização do cinema popular, Josafá revela, em uma fala curta, um desejo até então escondido:

Eu sonho um dia ver meus filmes em sala [...] de cinema! Né?! Eu não vou mentir. Eu não vou dizer que eu quero meu cinema só pra cá. Eu penso um dia, também, um filme que eu possa tratar... 'ó, o filme de Josafá foi mostrado nas salas de cinema do Brasil ou do mundo’ (Oliveira 2017).

\section{BIBLIOGRAFIA}

Abbema, Fabiana Maria Moro van. 2013. "Entre fazendeiros, donzelas e caiçaras: uma semiose cinematográfica de Cyro Matoso”. Dissertação (Mestrado em Comunicação e Linguagens), Universidade Tuiuti do Paraná (UTP), Curitiba, Paraná, Brasil.

Barthes, Roland. 2009. Roland Barthes por Roland Barthes. Lisboa: Edições 70.

Bauman, Zygmunt. 2001. Modernidade Líquida. Rio de Janeiro: Zahar.

Bordwell, David, Janet Staiger, e Kristin Thompson (orgs). 2015. The Classical Hollywood Cinema: Film Style and Mode of Production to 1960. Londres/Nova Iorque: Routledge.

Cabrera, Rodrigo Henrique. 2011. “Zé, o pintor de cinema”. Revista Overmundo. 4 de agosto de 2011. http://www.overmundo.com.br/overblog/ze-opintor-de-cinema (acessado em 08/04/2019).

Chartier, Roger. 1995. "Cultura popular: revisitando um conceito historiográfico.” Revista Estudos Históricos 8 (16), 179-192.

Chauí, Marilena. 1996. Conformismo e Resistência. São Paulo: Brasiliense.

Delamont, Sara, org. 2006. Narrative Methods. Londres: Thousand Oaks, Calif: SAGE Publications Ltd.

Duarte, Josafá Ferreira. 2016. “Josafá Ferreira Duarte - YouTube”. 2016. https://www.youtube.com/channel/UCwMp-cuZSo2EpQxAYJCXd-g (acessado em 01/11/2018). 
Espinosa, Júlio Garcia. 1970. Por un cine imperfecto. Caracas: Fondo Editorial Salvador de la Plaza.

Hall, Stuart. 1997. "A centralidade da cultura: notas sobre as revoluções culturais do nosso tempo”. Educação \& Realidade 22 (2), 15-46.

-——. 2014. A Identidade Cultural na Pós-Modernidade. Rio de Janeiro: Lamparina.

Illeris, Helene; Arvedsen, Karsten. 2012. "Fenômenos e eventos visuais: algumas reflexões sobre currículo e pedagogia da cultura visual”. Cultura das imagens: desafios para a arte e para a educação, organizado por Raimundo Martins e Irene Tourinho, 283-309. Santa Maria: Editora UFSM.

Le Masson, Yann; Poliakoff, Olga. 1962. "Manifeste pour un cinéma parallèle”. Positif, Juin de 1962. http://mauricedarmon.blogspot.com.br/2012/09/yann-le-masson-et-olgapoliakoff.html (acessado em 08/04/2019).

Lima, Dellani; Ikeda, Marcelo. 2010. Cinema de garagem: um inventário afetivo sobre o jovem cinema brasileiro do século XXI. Belo Horizonte/Fortaleza: SuburbanaCo.

Luna, Sergio. 2010. "La critica de la cultura después de la cultura". Estudios Visuales 7 (Centro de Documentación y Estudios Avanzados de Arte Contemporáneo), 100-113.

Lyra, Bernardette; Santana, Gelson (orgs). 2006. Cinema de bordas. São Paulo: A Lapis.

Lyra, Bernardette. 2009. "Cinema periférico de bordas”. Comunicação, Mídia e Consumo, março de 2009.

Martins, Alice Fátima. 2013. Catadores de sucata da indústria cultural. Goiânia: UFG.

Martins, Raimundo. 2015. "A cultura visual e a construção social da arte, da imagem e das práticas do ver". Arte, Educação e Cultura, organizado por Marilda Oliveira de Oliveira, 17-38. Santa Maria: Editora UFSM.

Neto, João Cabral de Melo. 2007. Morte e vida Severina. Rio de Janeiro: Alfaguara.

Oliveira, Paulo Passos de. 2013. "Entrevista presencial com Josafá Duarte.” Entrevista por Paulo Passos de Oliveira. Gravador de áudio digital. Sobral. 23/08/2013.

——_. 2016. "Entrevista por telefone com Josafá Duarte.” Entrevista por Paulo Passos de Oliveira. Gravador de áudio digital. Goiânia. 05/02/2016.

——_. 2017. "Entrevista presencial com Josafá Duarte.” Entrevista por Paulo Passos de Oliveira. Vídeo digital. Salgado dos Mendes. 26/01/2017.

Roger, Ronaldo. 2013. Forquilha Cinecordel (blog). Abril de 2013. Última modificação em 14 de maio de 2015. http://cinecordel.blogspot.com.br/ (acessado em 08/04/2019).

Sales, Fernanda. 2012. "Entrevista com Zé Pintor e Carlos Eduardo Magalhães Delírios de um Cinemaníaco”. RUA » Revista Universitária do Audiovisual 
(blog). 7 de novembro de 2012. http://www.rua.ufscar.br/entrevistacom-ze-pintor-e-carlos-eduardo-magalhaes-delirios-de-umcinemaniaco/ (acessado em 08/04/2019).

Santos, Yasmin Bidim Pereira dos. 2016. Filmes periféricos e as margens do cinema brasileiro: um estudo de caso a partir do longa-metragem Cartão Postal. Dissertação (Mestrado do Programa de Pós-Graduação em Imagem e Som), Universidade Federal de São Carlos, São Carlos, SP, Brasil.

Satler, Lara Lima. 2016. Tramas formativas em audiovisual [manuscrito]: a minha ação docente à luz das experiências audiovisuais coletivas. Tese (Doutorado do Programa de Pós-Graduação em Arte e Cultura Visual), Faculdade de Artes Visuais da Universidade Federal de Goiás, Goiânia, Goiás, Brasil.

Williams, Raymond. 1965. The Long Revolution. U.S.A.: Penguin Books.

\section{FILMOGRAFIA}

A história de um galo assado. Dir. Josafá Duarte. Brasil: Cinecordel. 2006.

Cadê meu zóculos. Dir. Josafá Duarte. Brasil: Cinecordel, 2015. https://youtu.be/RwQ8NnVI5nw (acessado em 08-IV-2019).

Casablanca. Dir. Michael Curtiz. EUA: Warner Bros, 1942.

Corisco \& Dadá. Dir. Rosemberg Cariry. Brasil: Cariri Filmes, 1996.

Delírios de um cinemaníaco. Dir. Carlos Eduardo Magalhães e Felipe Leal Barquete. Brasil: Filmes para bailar/Fora do Eixo, 2013.

https://youtu.be/ZA4n31pWjlA (acessado em 08-IV-2019).

Escapei fedendo. Dir. Josafá Duarte. Brasil: Cinecordel, 2017.

https://youtu.be/n5NrHlhhglM (acessado em 08-IV-2019).

O auto da compadecida. Dir. Guel Arraes. Brasil: Columbia Tristar, 1999.

O casamento de Vicência. Dir. Djalma Prado e Ronaldo Roger. Brasil: Filmarte Filmarte, 2011. http://cinecordel.blogspot.com.br/ (acessado em 08-IV2019).

O homem que queria enganar a morte. Dir. Josafá Duarte. Brasil: Cinecordel, 2014a. https://youtu.be/PRE7YvNChcg (acessado em 08-IV-2019).

Pássaros fantasmas: uma aventura na selva. Dir. Josafá Duarte. Brasil: Cinecordel, 2014b.

Por debaixo dos panos. Dir. Josafá Duarte. Brasil: Filmarte Filmes. 2010. https://youtu.be/Aq936cBvvMg (acessado em 08-IV-2019). 